\title{
Lower oxidative damage and cell wall loosening, mediated or not by auxin, as part of the tolerance mechanism of Paubrasilia echinata morphotypes in the shade and full sun
}

\author{
Vinícius Novo Gama1 (1), Leonardo Valandro Zanetti ${ }^{1}$ (D), Bernardo Pretti Becacici Macieira', 2* (1) \\ and Geraldo Rogério Faustini Cuzzuol ${ }^{1}$ (B)
}

Received: November 27, 2020

Accepted: June 22, 2021

\begin{abstract}
Paubrasilia echinata presents three morphotypes that differ from each other in leaf morphology (small morphotype$\mathrm{SM}$, medium morphotype-MM, and large morphotype-LM) with indications of divergence between them regarding irradiance tolerance. The present study aimed to identify possible physiological and growth patterns in $P$. echinata morphotypes under contrasting irradiance. The growth and photosynthesis of SM were inhibited in the full sun, and those of MM and LM, in the shade. The auxin contents of the three morphotypes increased in the full sun. However, in MM and LM, this increase was 5 times greater. The oxidative damage (hydrogen peroxide- $\mathrm{H}_{2} \mathrm{O}_{2}$ and lipid peroxidation-MDA content) of SM were higher in the full sun and of MM and LM in the shade. The stem hemicelluloses and $\mathrm{CO}_{2}$ assimilation decreased in shade for SM, and sun for MM and LM. The shade tolerance of SM and the full sun tolerance of MM and LM were associated with lower oxidative damage and cell wall loosening (lower hemicelluloses content) in the photo-promoted treatments. The integration of the lower oxidative damage with cell wall loosening seems to represent an essential part of the tolerance mechanism of P. echinata morphotypes in the shade and full sun.
\end{abstract}

Keywords: auxin, Brazilwood, hemicelluloses, oxidative stress, photo-assimilation

\section{Introduction}

The few studies about the physiology of sun-tolerant (pioneer) and shade-tolerant (non-pioneer) tropical forest tree species under contrasting solar irradiances (shade and full sun) in the early growth phase have presented unclear responses regarding growth (Souza \& Válio 2003), photosynthesis (Ribeiro et al. 2005), and oxidant metabolism (Contin et al. 2014) between these two functional classes.
This makes it difficult to understand the ecophysiology of sun-tolerant and shade-tolerant tree species of tropical forests under shade and full sun conditions.

Although the sun-tolerant and shade-tolerant species are known by their requirement of full sun and shade for establishment and growth (Finegan 1984; Swaine \& Whitmore 1988; Whitmore 1991), respectively, some tropical tree species have not presented a well-defined growth pattern among these two successional classes under

1 Laboratório de Fisiologia e Bioquímica Vegetal, Departamento de Ciências Biológicas, Centro de Ciências Humanas e Naturais,

Universidade Federal do Espírito Santo, 29075-910, Vitória, ES, Brazil

2 Laboratório de Anatomia da Madeira, Departamento de Ciências Florestais e da Madeira, Centro de Ciências e Engenharia Agronômica,

Universidade Federal do Espírito Santo, 29550-000, Jerônimo Monteiro, ES, Brazil

* Corresponding author: bernardopretti@gmail.com 
shade and full sun conditions (Souza \& Válio 2003). For these authors, inter-specific differences in growth parameters such as root:shoot ratio and leaf mass area did not show differentiated responses between sun-tolerant and shadetolerant species under shade and full sun. In general, the species of these two functional classes exhibited higher relative growth rates and net assimilation rates in full sun (Souza \& Válio 2003) or in intermediated shade conditions in relation to deep shade (Kitajima 1994).

Although tropical pioneer species are characterized by a level of photosynthesis higher than the non-pioneer species (Whitmore 1991; Huc et al. 1994; Nogueira et al. 2004; Portes et al. 2010), this variable did not present a well-defined pattern of responses in some tropical shadetolerant and sun-tolerant tree species under contrasting solar irradiance. In general, some sun-tolerant and shadetolerant tropical trees presented higher photosynthesis in full sun conditions, showing that this variable did not show a clear difference between these two successional groups under contrasting intensity irradiance (Kitajima 1994; Ribeiro et al. 2005).

Like photosynthesis, almost nothing is known about carbon allocation in sun-tolerant and shade-tolerant morphotypes of tropical trees under contrasting irradiance (shade and full sun) conditions. Most of the photoassimilated carbon that is not used in the metabolism is stored in the form of structural carbon reservoirs that make up the microfibrils of cellulose, hemicelluloses, and lignin of the cell wall (Schädel et al. 2010). These polymers represent $40-60 \%$ of the dry mass of plants (Thomas \& Martin 2012). In addition to the structural function, cell wall polymers act as an energy reserve, and may experience some cycling under environmental stress (Le Gall et al. 2015). One of a few studies with sun-tolerant and shade-tolerant tropical trees submitted to contrasting irradiance revealed that lignin deposition in shade-tolerant Paratecoma peroba may be stimulated by the exposure to full sun conditions (Paradizo et al. 2015). As for cellulose and hemicelluloses, information on the irradiance effects on these carbon polymers contents in trees are scarce (Le Gall et al. 2015).

Although some pioneer tropical trees are more tolerant against the oxidative stress than non-pioneer trees in natural field conditions (Esposito et al. 2018), the oxidant reactions of some sun-tolerant and shade-tolerant juvenile tropical trees under photo-inhibitory conditions (shade and full sun, respectively) did not exhibit very well defined traits between these two functional classes (Contin et al. 2014). The most abundant, reactive and stable reactive oxygen species is hydrogen peroxide- $\mathrm{H}_{2} \mathrm{O}_{2}$ (Choudhury et al. 2017), a potent lipid peroxidation agent detected by the increase of malondialdehyde-MDA (Asada \& Asada 1999) in plants under stress situations. Under such oxidant conditions, including low and intense solar irradiance, the excess of $\mathrm{H}_{2} \mathrm{O}_{2}$ may affect photosynthesis (Liu et al. 2016) resulting in growth inhibition by limiting the amount of photoassimilates (Gaburro et al. 2015; Portela et al. 2019; Gama et al. 2019). The $\mathrm{H}_{2} \mathrm{O}_{2}$ can also affect growth by blocking the auxin synthesis (Kurepin et al. 2007; Gong et al. 2014), which promotes cell expansion and stem elongation (Sofo et al. 2004; Baroniya et al. 2014; Kataria et al. 2014). Among the few studies about oxidant reactions in native tropical trees, Contin et al. (2014) showed that the juvenile sun-tolerant Guazuma ulmifolia accumulated $\mathrm{H}_{2} \mathrm{O}_{2}$ and MDA under a high irradiance regime while the contents of these compounds did not differ among the contrasting irradiance regimes for Ceiba speciosa. Differently from expected, these authors concluded that the sun-tolerant plant is more sensitive to high irradiance and that the photo-oxidative damage repair in this functional group species does not always perform better than in the shade-tolerant species. In contrast, Favaretto et al. (2011) concluded that, in full sun conditions, tropical pioneer species present a higher antioxidant capacity than non-pioneer ones. In addition, nothing is known about the oxidative metabolism of shadetolerant and sun-tolerant tropical trees under contrasting solar irradiance.

These contradictory or insufficiently clear results regarding growth, photosynthesis, and oxidant reactions in the juvenile phase of sun-tolerant and shade-tolerant tropical forest trees under contrasting solar irradiance (shade and full sun) regimes have been attributed, in particular, to interspecific divergences (Souza \& Válio 2003; Favaretto et al. 2011). In general, such studies have used species from distant taxonomic levels at the genus and family levels. The most used sun-tolerant genera were been Cecropria, Croton, Guazuma, Senna, and Schinus, and the shade-tolerant ones were Cariniana, Cedrela, Ceiba, Esenbeckia, Hymenaea, and Tabebuia, all of them from very distantly related families.

In order to overcome this situation, it is necessary to investigate closely related species, or to analyse species with morphotypes differing in their tolerance to solar irradiance intensity. These types of studies are rare in tropical forests. Organisms with this intraspecific profile may provide a better understanding of the physiological reactions in tropical trees tolerant to full sun or shade conditions. Paubrasilia echinata (Fabaceae), known as Brazilwood, is a tropical tree with the intraspecific aforementioned profile. This species has three morphotypes that differ regarding the morphology of their leaflets: the small, medium, and large leaflet morphotypes (Juchum et al. 2008). These three morphotypes also differ in their early growth habit. The small morphotype has been considered as shade-tolerant (Mengarda et al. 2009) and the medium morphotype as sun-tolerant (Gama et al. 2019). The criteria used by these authors to classify the morphotype habits were based on the irradiance that offered the best growth and photosynthesis condition for each morphotype. Regarding the large morphotype, the relation between its growth habit and the irradiance level is unknown.

The purpose of the present study was to identify possible physiological and morphological patterns in the 
morphotypes of sun-tolerant and shade-tolerant varieties of P. echinata under contrasting shade and full sun conditions, therefore controlling taxonomic divergences. We also intend to contribute to increase the knowledge about the physiological mechanisms of tropical trees tolerant to shade and full sunlight under contrasting irradiance. We hypothesize that the low growth and photosynthesis of the small morphotype (shade-tolerant) in the full sun condition and of the medium and large morphotypes (suntolerant) in the shaded environment was due to the higher oxidant reactions and lower auxin and cell wall polymer concentrations at the photo-inhibitory conditions.

\section{Materials and methods}

\section{Study area and experimental design}

The experiment was conducted at the Departamento de Ciências Biológicas da Universidade Federal do Espírito Santo (20¹8'52" S and 40¹9'06” W) at Vitória, Espírito Santo state, Brazil. The plants were propagated from seeds of the small, medium, and large leaf morphotypes of Paubrasilia echinata Lam. - Gagnon, H.C.Lima \& G.P.Lewis (Fabaceae) grown in plastic pots of $20 \mathrm{~L}$ containing soil from the lowland Atlantic forest where this species naturally grows. The soil was collected at $30 \mathrm{~cm}$ below the surface. The soil chemical and physical characteristics are presented in Table 1. According to Cuzzuol et al. (2013), the soil was not fertilized.

The plants were cultivated inside a nursery $(6.0 \mathrm{~m}$ length $\times 1.5 \mathrm{~m}$ depth $\times 2.0 \mathrm{~m}$ height) covered by black polyethylene nets plus solar interference film (Insulfilm ${ }^{\mathrm{TM}}$, São Paulo, Brazil), resulting in a solar irradiance of approximately $50 \%$ of photosynthetic photon flux density (PPFD) $(1,000 \pm 150$ $\mu \mathrm{mol} \mathrm{m} \mathrm{m}^{-2} \mathrm{~s}^{-1}$ ) on a sunny day at 9:00 a.m. The plants were irrigated daily with tap water, and cultivated under these conditions for one year, when they exhibited the proper structural dimensions for the beginning of this experiment.

After this period of biomass growth, plants with $18 \pm 3$ $\mathrm{cm}$ height and $4 \pm 1$ leaves were divided in two lots. One lot of 20 plants of each morphotype was transferred to the other nursery, covered with black polyethylene nets plus solar interference film, in order to reduce the solar irradiance to approximately $10 \%$ PPFD $\left(200 \pm 80 \mu \mathrm{mol} \mathrm{m}^{-2} \mathrm{~s}^{-1}\right.$ at midday $)$ simulating the understory environment of a tropical forest. The other lot (20 plants per morphotype) was exposed to full sun or $100 \%$ PPFD $\left(2,000 \pm 250 \mu \mathrm{mol} \mathrm{m}^{-2} \mathrm{~s}^{-1}\right.$ PAR at midday $)$ on cloudless days. The PPFD inside the nursery and in full sun was measured with a spectroradiometer (Spectrum Technologies, Inc., Illinois, USA) every $1 \mathrm{~min}$ for $10 \mathrm{~min}$.

The experiment began in Jun 2013 and ended in March 2014. The average relative humidity, rainfall, and temperature of each month were $80 \pm 15 \%, 75 \pm 30 \mathrm{~mm}$, and $24 \pm 6{ }^{\circ} \mathrm{C}$, respectively, recorded by the meteorological station of the Instituto Capixaba de Pesquisa, Assistência Técnica e Extensão Rural (INCAPER), located 200 meters from the study site. The plants of both lots were irrigated daily with tap water. Every two weeks, the position of the lots was randomly shifted within each treatment to avoid environmental influences other than the solar irradiance.

In each treatment, we used seven repetitions for growth and cell wall polymers analysis, and five repetitions for photosynthetic and biochemical analyses. Each repetition was composed by one plant.

\section{Growth analyses}

At the beginning and at the end of the experiment, the stem height (stem base until terminal bud) and diameter (stem base), root, stem and leaf dry mass, and total leaflet area of the plants from each treatment were measured according to Mengarda et al. (2009). To obtain the dry mass, the plant material was oven-dried at $60{ }^{\circ} \mathrm{C}$ until reaching constant weight. The leaflet area was determined using a leaf area meter (LI-COR 3100, Nebraska, USA). Based on the data obtained the leaf mass area-LMA (leaf dry mass/ leaf area), root:shoot ratio (root dry mass/shoot dry mass), relative growth rate-RGR $\left[\left(\mathrm{nTDM}_{2}-1 \mathrm{nTDM}_{1}\right) /\left(\mathrm{t}_{2}-\mathrm{t}_{1}\right)\right]$, and net assimilation rate-NAR $\left[\left(\mathrm{TDM}_{2}-\mathrm{TDM}_{1}\right) /\left(\mathrm{t}_{2}-\mathrm{t}_{1}\right) \times\right.$ $\left.\left(\operatorname{lnL} A_{2}-\operatorname{lnL} A_{1}\right) /\left(L_{2}-L_{1}\right)\right]$ were calculated, where $\ln =$ natural logarithm, TDM = total dry mass, $\mathrm{LA}=$ leaf area, $\mathrm{t}$ = time, and index $x_{1}=$ initial value and index ${ }_{2}=$ final value, according to Lambers \& Poorter (1992).

\section{Gas exchange and chlorophyll a fluorescence}

Gas exchange and chlorophyll a fluorescence measurements were performed on the middle portion of the fully expanded mature leaves from the third apical node, on a sunny day, before the growth analysis, using portable photosynthesis systems for gas exchange (LI 6400XT, Li-Cor, Inc., Lincoln, NE, USA) equipped with red and blue light sources (LI-6400-02B LED) in order to maximize stomatal opening, and with a $2 \mathrm{~cm}^{2}$ integrated fluorescence chamber (LI-6400-40, LI-COR Inc.). In the case of the small morphotype, two leaflets were used to fill the entire chamber area. Gas exchange was conducted

Table 1. Physical and chemical characteristics of the soils of lowland formation of the Atlantic forest of Espírito Santo state, Brazil (Santos et al. 2004). C is soil organic carbon content, $\mathrm{N}$ is soil nitrogen content, SEB is soil sum exchangeable bases, CEC is soil cation exchange capacity, $\mathrm{V}$ is soil cation saturation and $\mathrm{P}$ is soil phosphorus content.

\begin{tabular}{|c|c|c|c|c|c|c|c|c|c|c|c|}
\hline deep (cm) & sand & silt $\%$ & clay & $\mathrm{Cg} \mathrm{kg}^{-1}$ & $\mathrm{Ng} \mathrm{kg}^{-1}$ & $\mathrm{C} / \mathrm{N}$ & $\mathrm{pH}$ & SEB cmolc kg ${ }^{-1}$ & CEC cmolc kg ${ }^{-1}$ & V \% & P mg kg \\
\hline $0-11$ & 91 & 4 & 5 & 0.90 & 0.07 & 12.9 & 5.3 & 2.6 & 4.2 & 62 & 2 \\
\hline $11-41$ & 79 & 5 & 16 & 0.60 & 0.07 & 8.6 & 5.2 & 1.5 & 3.6 & 42 & 2 \\
\hline
\end{tabular}


under an artificial saturating light of $500 \mu \mathrm{mol}$ photons $\mathrm{m}^{-2} \mathrm{~s}^{-1}$ for shade and 1,000 $\mu \mathrm{mol}$ photons $\mathrm{m}^{-2} \mathrm{~s}^{-1}$ for full sun, previously defined by light-response curves (A/PPFD). The humidity of the air inside the chamber was adjusted by the equipment itself by $60 \%$, keeping it standardized for all treatments. The respiration rate in the dark $(\mathrm{Rd})$ was determined two hours after the end of the light period and calculated through the A/PPFD ratio. The Rd was measured during the night, without any light, in order to evaluate the real mitochondrial respiratory activity of the plants. The net $\mathrm{CO}_{2}$ assimilation rate $(A)$, stomatal conductance to water vapor $(g s)$, transpiration $(E)$, and internal $\mathrm{CO}_{2}$ concentration $(\mathrm{Ci})$ were measured from 08:00 to 10:00 a.m. under an external $\mathrm{CO}_{2}$ concentration of $400 \mu \mathrm{mol} \mathrm{mol}^{-1}$ and an average temperature of $27^{\circ} \mathrm{C}$. Based on these gas exchange variables, the water-use efficiency $(W U E=A / E)$, and the instantaneous carboxylation efficiency $(\Phi c=A$ / Ci) were calculated.

The determination of chlorophyll $a$ fluorescence started two hours after the end of the light period with a fluorometer coupled to a gas exchange system. The leaves were preadapted to dark for $30 \mathrm{~min}$ and then initially exposed to a faint red-distant pulse $\left(0.03 \mu \mathrm{mol}\right.$ photons $\left.\mathrm{m}^{-2} \mathrm{~s}^{-1}\right)$ for determination of the initial fluorescence $\left(F_{0}\right)$. Then, a pulse of saturating light with solar irradiance of 8,000 $\mu \mathrm{mol}$ photons $\mathrm{m}^{-2} \mathrm{~s}^{-1}$ with $0.8 \mathrm{~s}$ of duration was applied to estimate the maximum emitted fluorescence $\left(F_{\mathrm{m}}\right)$. The variable fluorescence $\left(F_{v}\right)$ was determined by the difference between $F_{0}$ and $F_{\mathrm{m}}$. Based on the values of $F_{0}$ and $F_{\mathrm{m}}$, the maximum photochemical yield of photosystem II (PSII) $F_{\mathrm{v}} /$ $F_{\mathrm{m}}=\left(F_{\mathrm{m}}-F_{0}\right) / F_{\mathrm{m}}$ (Butler 1978) was calculated. We removed all the leaflets from the first two mature, apical, fully expanded leaves used in photosynthesis analyses in order to perform the biochemical analysis (auxin, hydrogen peroxide, and lipid peroxidation).

Auxin

Samples of $4 \mathrm{~g}$ of fresh leaf tissue were ground in $15 \mathrm{~mL}$ of methanol (pro analysis) containing $1.5 \mathrm{~mL}$ of $1 \mathrm{M} \mathrm{HCl}$, and the homogenate was kept in the dark at $4{ }^{\circ} \mathrm{C}$ for $12 \mathrm{~h}$ (Guo et al. 2010). The extracts were then centrifuged at 4.324 $\times g$ for $15 \mathrm{~min}$. The supernatants were reduced to $3 \mathrm{~mL}$ in an ice bath under a laminar flow hood. Indol-3-acetic acid (IAA) was extracted from a mixture of $1 \mathrm{~mL}$ of the extract, $1 \mathrm{~mL}$ of $1 \%$ 4-dimethylaminobenzaldehyde (PDAB; Ehrlich reagent, Sigma-Aldrich), and $0.45 \mathrm{~mL}$ of $36 \% \mathrm{HCl}$, for 40 min at $25^{\circ} \mathrm{C}$, and the absorbances were read at $583 \mathrm{~nm}$ in a spectrophotometer (Thermo Scientific GENESYS 10S UV-Vis Spectrophotometer, Massachusetts, USA). Then, the mixtures were heated in a water bath at $70^{\circ} \mathrm{C}$ for $150 \mathrm{~min}$ and again read at $583 \mathrm{~nm}$. The absorbances were applied to standard curves of 0 to $10 \mu$ g of IAA obtained from SigmaAldrich, and the results were expressed in $\mu \mathrm{g}$ of auxin IAA per gram of dry mass. The pellet from the centrifugation was dried in an oven at $50^{\circ} \mathrm{C}$ for 5 days, and its weight was used to express the results by dry mass.

\section{Hydrogen peroxide contents $\left(\mathrm{H}_{2} \mathrm{O}_{2}\right)$ and lipid peroxidation (MDA) determination}

The extracts for determination of the $\mathrm{H}_{2} \mathrm{O}_{2}$ and MDA contents were obtained from $250 \mathrm{mg}$ of fresh leaf tissue. The samples were ground in liquid nitrogen plus $20 \%$ polyvinylpolypyrrolidone (PVPP), homogenized in $5 \mathrm{~mL}$ of $0.1 \%$ trichloroacetic acid (TCA), and centrifuged at 10,000 $\times g$ for 10 min at $4{ }^{\circ} \mathrm{C}$. The $\mathrm{H}_{2} \mathrm{O}_{2}$ content was determined following the method of Alexieva et al. (2001). The reaction medium consisted of $0.5 \mathrm{~mL}$ of the extract supernatant, $0.5 \mathrm{~mL}$ of $100 \mathrm{mM}$ potassium phosphate buffer ( $\mathrm{pH} 7)$, and $2 \mathrm{~mL}$ of $1 \mathrm{M}$ potassium iodide. The reaction occurred in the dark for $1 \mathrm{~h}$, the absorbance was read at $390 \mathrm{~nm}$, and the $\mathrm{H}_{2} \mathrm{O}_{2}$ content was determined using a standard curve.

The determination of the MDA content, the end product of lipid peroxidation, followed the method of Buege \& Aust (1978), in a reaction with TCA. Aliquots of the supernatant were added to the reaction medium $(0.5 \%$ $\mathrm{w} / \mathrm{v})$ of 2-thiobarbituric acid (TBA) and $10 \%(\mathrm{w} / \mathrm{v}) \mathrm{TCA}$ and incubated at $95^{\circ} \mathrm{C}$ for $30 \mathrm{~min}$. The reaction was then stopped by flash-cooling on ice, and readings were performed at 535 and $600 \mathrm{~nm}$. The MDA content was calculated from the extinction coefficient of $155 \mathrm{mM}^{-1} \cdot \mathrm{cm}^{-1}$ by applying the formula MDA content $(\mu \mathrm{M})=[(\mathrm{A} 535-\mathrm{A} 600) / 1.56] \times 105$ (Buege \& Aust 1978). The absorbances were read in Genesys 5.0 spectrophotometer (Thermo Scientific, Madison, WI, USA). The determination of the dry mass followed the same method used for auxin.

\section{Cell wall polymers (CWP)}

Leaf and stem segments of the dried plants used in the growth analysis were ground in a ball mill (Tecnal TE-350, São Paulo, Brazil). The CWP concentrations were assessed following the gravimetric analysis by chemical precipitation. For cellulose analysis $100 \mathrm{mg}$ of ground samples were treated according to Brendel et al. (2000), with $80 \%$ acetic acid and $69 \%$ nitric acid added and placed in a water bath at $100^{\circ} \mathrm{C}$ for $60 \mathrm{~min}$. After cooling, $99 \%$ ethanol was added to the samples, homogenized, centrifuged, and the supernatant discarded. The samples were then washed sequentially in $99 \%$ ethanol, deionized water, $17 \% \mathrm{NaOH}$, deionized water, deionized water + acetic acid, and deionized water again. Between each wash, the samples were centrifuged and the supernatants discarded. After the last wash, the samples were dried and weighed. This weight was then subtracted from the initial weight of the sample, with the result representing the cellulose fraction.

Hemicelluloses concentrations were assessed following the protocol of Schädel et al. (2010) using $50 \mathrm{mg}$ of ground samples, but replacing the starch enzymatic extraction with dimethyl sulfoxide $90 \%$ (Carpita \& Kanabus 1987). The free precipitate of soluble sugars and starch was dissolved 
in neutral detergent (sodium tetraborate decahydrate, ethylendiaminetetra acetic acid-EDTA, sodium dodecyl sulphate, triethylene glycol, dibasic sodium phosphate, and deionized water) to extract proteins, low molecular weight carbohydrates, lipids, and pectins, which were separated by centrifugation and discarded. The pellet ('total cell wall fraction' containing cellulose, hemicelluloses, and lignin) was washed (hot deionized water, acetone, and deionized water), dried overnight, and the dry mass was weighed on a $0.01 \mathrm{mg}$ scale. Then, the acid detergent $\left(\mathrm{H}_{2} \mathrm{SO}_{4}\right.$ and hexadecyl trimethylammonium bromide) was added to the pellet, homogenized, boiled for hemicellulose extraction, centrifuged, and the supernatant containing hemicelluloses was discarded. The pellet (containing the 'cellulose and lignin fraction') was washed with deionized water and acetone, dried, and the dry mass was weighed. Total hemicelluloses concentrations were calculated as the gravimetric difference between the 'total cell wall fraction' and the 'cellulose and lignin fraction'.

The extraction and determination of lignin were made according to the methodology of Dos Santos et al. (2008) with $150 \mathrm{mg}$ of sample material and reading at $280 \mathrm{~nm}$ using a spectrophotometer (Thermo Scientific GENESYS 10S UV-Vis Spectrophotometer, Massachusetts, USA). After that, $50 \mathrm{mM}$ potassium-sodium phosphate buffer ( $\mathrm{pH} 7$ ) was added and the ground samples were centrifuged and the supernatant discarded. The pellet was washed with different solutions: $50 \mathrm{mM}$ phosphate buffer $\left(\mathrm{pH}\right.$ 7), Triton ${ }^{\circ}(\mathrm{pH}$ 7), $\mathrm{NaCl}$ buffer ( $\mathrm{pH} 7$ ), deionized water and acetone. After the chemical washes, the pellet was dried representing the protein-free cell wall fraction, of which $50 \mathrm{mg}$ were weighed and thioglycolic acid and $2 \mathrm{M} \mathrm{HCl}$ were added. The samples were incubated in a water bath, centrifuged, and washed with deionized water. Next, $0.5 \mathrm{M} \mathrm{NaOH}$ was added, and the samples were incubated at $30^{\circ} \mathrm{C}$ for $18 \mathrm{~h}$ while under constant shaking, centrifuged, and the supernatant was stored. The pellet was washed with $0.5 \mathrm{M} \mathrm{NaOH}$, centrifuged, and the supernatant was added to the aforementioned one. Total supernatant was acidified with $\mathrm{HCl}$ and left at $4{ }^{\circ} \mathrm{C}$ for $12 \mathrm{~h}$, without shaking, for precipitation. After this time, the samples were washed with deionized water, centrifuged, and the supernatant discarded. The precipitate was dried and resuspended in $0.5 \mathrm{M} \mathrm{NaOH}$. A lignin solution (Sigma") was used to construct the standard curve at concentrations of 0-500 $\mu \mathrm{g} \mu \mathrm{L}^{-1}$.

\section{Plasticity index}

The plasticity index (PI) was used to evaluate the plasticity of the different variables analyzed following Valladares et al. (2006). The PI was calculated from the difference between the average maximum and minimum values for each treatment, divided by the average of the maximum value. The closer to 1 the value, the higher the plasticity of the variable.

\section{Statistical analysis}

The experiment was designed as a factorial, with three morphotypes and two solar irradiance levels (3 $\times 2$ ). The data were analyzed in InfoStat (https://www. infostat.com/, InfoStat Group, FCA, National University of Córdoba, Argentina) for the homogeneity and normal distribution analysis using the Levene and Shapiro-Wilk tests, respectively. Analysis of variance (two-way ANOVA) was applied, and means were compared using the Tukey's test $(P<0.05)$.

\section{Results}

\section{Growth analyses}

As expected, the small morphotype (SM) grew more in height and total dry mass (TDM), presented a higher relative growth rate (RGR), and a net assimilation rate (NAR) in the shade, while the medium (MM) and large morphotypes (LM) did so in the full sun condition (Fig. 1A-D. The three morphotypes allocated more biomass to the root in the full sun status, indicated by the higher root:shoot (R:S) ratio under this condition (Fig. 1E). The full sun condition also raised the leaf mass area (LMA) of the three morphotypes. Their comparison within each treatment showed the higher values for height, TDM, RGR, and NAR were observed for MM and LM, compared to $S M$, under the full sun condition (Fig. 1A-D). In this light intensity, higher values of R:S ratio were observed in SM and MM compared to LM (Fig. 1E). Yet, under the full sun condition, the highest value for LMA was found in MM, which did not vary between the other two morphotypes (Fig. 1F). In the shade, the height, TDM, $R G R, N A R$, and R:S presented the highest values in SM, showing no differences between MM and LM (Fig. 1A-E). Under that same condition, the LMA did not show any difference between the three morphotypes. The MM and LM exhibited the highest adjustment capacity (plasticity index-PI) on height, TDM, RGR, and NAR compared to SM (Tab. 2). Regarding R:S, the MM showed the highest values for PI compared to the other two morphotypes. The LMA did not vary among the three morphotypes. Among the growth variables, TDM and NAR presented the highest PI values, which approached the maximum value (1.0).

\section{Auxins}

The higher stem growth observed in the MM and LM under the full sun condition was accompanied by high auxin IAA concentrations under this irradiance (Fig. 2). Contrary to the expected results, the IAA of the SM showed a higher value under the full sun. Comparing the three morphotypes within each treatment, in the full sun condition the IAA levels found in MM and LM were similar to each other and 
higher than the one reported for SM. In the shade, the SM presented the highest IAA concentration compared to MM and LM, which presented similar values. The adjustment capacity of IAA in the MM and LM were very high, being close to the maximum PI value (Tab. 2).

\section{Gas exchange and chlorophyll a fluorescence}

Similar to growth and IAA, the gas exchange variables followed the same pattern. Thus, the SM showed the highest photosynthetic performance in the shade, while MM and LM did so under the full sun (Fig. 3 ). The net carbon assimilation rates- $A$, intercellular $\mathrm{CO}_{2}$ concentration$C i$, transpiration- $E$, stomatal conductance-gs, water-use efficiency-WUE, instantaneous carboxylation efficiency- $\Phi c$, and quantum yield of the PSII- $F_{V} / F_{M}$ (Fig. 3A-G) of the SM presented the highest values in the shade while for the MM and LM the highest values for these variables were found under the full sun condition. The three morphotypes presented their highest respiration rates in the dark-Rd (Fig. 3H) under full sun irradiance. When comparing the three morphotypes within each treatment, in full sun condition, the highest values of $A, C i, E, g s, W U E$, $\Phi_{c}$ and $F_{\mathrm{V}} / F_{\mathrm{M}}$ (Fig. 3A-G) were observed on MM and LM, and of Rd on SM (Fig. 3H). In the shade, the highest values of $A$ (Fig. 3A), E, gs, WUE, $\Phi$ c and $F_{\mathrm{V}} / F_{\mathrm{M}}$ (Fig. 3D-G) occurred in $\mathrm{SM}$ and of Rd values on the MM and LM (Fig. $3 \mathrm{H}$ ). Yet, in the shade, the values for $\mathrm{Ci}$ (Fig. 3B) did not show any difference among the three morphotypes. The MM and LM presented a higher adjustment capacity regarding the variables $A, E$, $W U E$, and $\Phi c$ for contrasting irradiance conditions, while
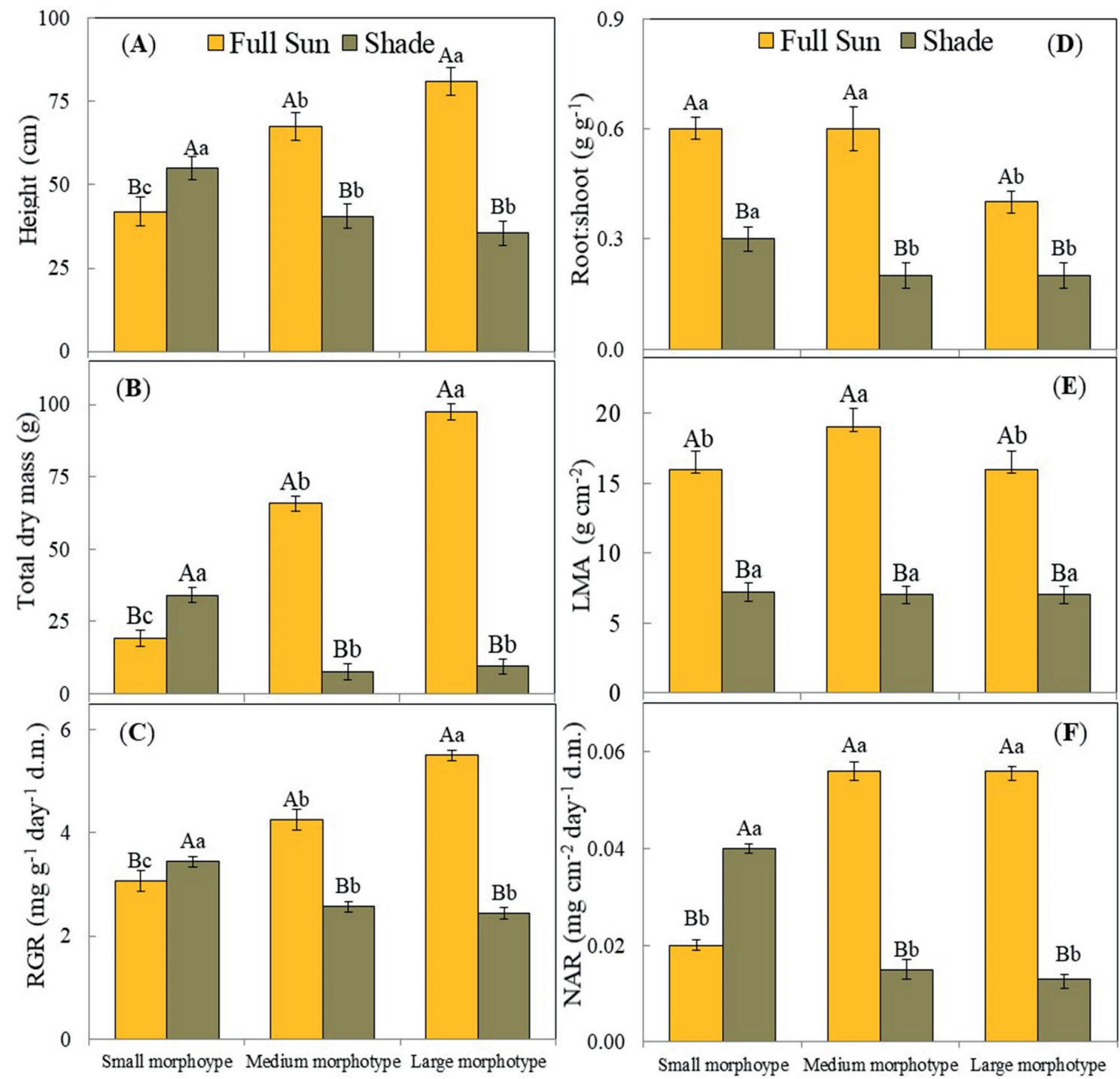

Figure 1. Height (A), total dry mass $(\mathbf{B})$, root:shoot $(\mathbf{D})$, LMA (E), RGR (C) and NAR (F) of the small, medium and large morphotypes of Paubrasilia echinata under full sun and shade. The bars represent the standard error of the mean. The differences between treatments are indicated by capital letters (A, B), whereas the differences between morphotypes within each treatment are indicated by lower case letters $(a, b)$ by Tukey's test $(P<0.05)$. LMA is leaf mass area, RGR is relative growth rate and NAR is net assimilation rate. 
for SM the highest PI occurred for $F_{\mathrm{V}} / F_{\mathrm{M}}$ and Rd (Tab. 2). The PI of $C i$ and gs did not vary significantly among the three morphotypes.

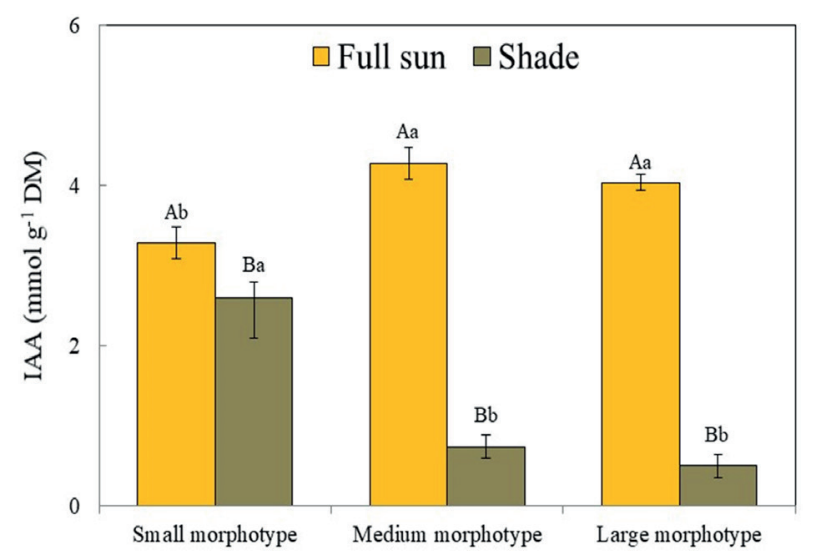

Figure 2. Indol-3-acetic acid (IAA) concentrations in leaf of the small, medium and large morphotypes of Paubrasilia echinata under full sun and shade. The bars represent the standard error of the mean. The differences between treatments are indicated by capital letters (A, B), whereas the differences between morphotypes within each treatment are indicated by lower case letters $(a, b)$ by Tukey's test $(P<0.05)$.

\section{Hydrogen peroxide and lipid peroxidation}

The highest contents of $\mathrm{H}_{2} \mathrm{O}_{2}$ and MDA in MM and LM were observed in the shade condition, while for SM this result was observed in the full sun (Fig. 4A-B). Comparing the three morphotypes within each treatment, the SM presented the highest $\mathrm{H}_{2} \mathrm{O}_{2}$ and MDA in the full sun. Under this irradiance, the values of these variables in LM were higher than MM. In the shade, the MM and LM morphotypes presented the highest values. Under that irradiance, the values of these variables did not differ among $\mathrm{LM}$ and $\mathrm{MM}$. Analysing the adjustment capacity of $\mathrm{H}_{2} \mathrm{O}_{2}$ and MDA to contrasting irradiance conditions, the SM showed the highest PI, which approached the maximum value (Tab. 2). In turn, the PI of these variables was not significantly different between MM and LM.

\section{Cell wall polymers}

Some small differences between treatments occurred regarding cellulose and hemicelluloses, and more pronounced differences were found regarding lignin (Fig. 5). The highest cellulose content was observed in the leaves of LM in the shaded condition (Fig. 5A) and no differences were found among the treatments in the leaves of the other

Table 2. Plasticity index of growth, photosynthesis, and biochemical variables of small, medium and large morphotypes of Paubrasilia echinata plants subjected to contrasting irradiance. TDM is total dry mass, R:S is root:shoot ratio, LMA is leaf mass area, RGR is relative growth rate, NAR is net assimilation rate, $A$ is net $\mathrm{CO}_{2}$ assimilation rate, $\mathrm{Ci}$ is internal $\mathrm{CO}_{2}$ concentration, $E$ is transpiration, $g s$ is stomatal conductance to water vapor, WUE is water-use efficiency, $\Phi$ c is efficiency instantaneous of carboxylation, $F_{\mathrm{V}} / F_{\mathrm{M}}$ is maximum photochemical yield of PSII, $\mathrm{Rd}$ is respiration rate in the dark, IAA is Indol-3-acetic acid, $\mathrm{H}_{2} \mathrm{O}_{2}$ is hydrogen peroxide, MDA is malondialdehyde, Cel. is cellulose, Hem. is hemicelluloses and Lig. is Lignin. Different letters in the same line indicate statistically significant differences by Tukey's test $(P<0.05)$.

\begin{tabular}{|c|c|c|c|c|}
\hline \multirow{2}{*}{ Variables } & \multirow{2}{*}{ Category } & \multicolumn{3}{|c|}{ Morphotypes } \\
\hline & & Small & Medium & Large \\
\hline High & \multirow{9}{*}{ Growth } & $0.2^{c}$ & $0.4^{\mathrm{b}}$ & $0.6^{a}$ \\
\hline TDM & & $0.4^{\mathrm{b}}$ & $0.9^{\mathrm{a}}$ & $0.9^{\mathrm{a}}$ \\
\hline $\mathrm{R}: \mathrm{S}$ & & $0.5^{\mathrm{b}}$ & $0.7^{\mathrm{a}}$ & $0.5^{\mathrm{b}}$ \\
\hline LMA & & 0.6 & 0.6 & $0.6^{\text {n.s. }}$ \\
\hline RGR & & $0.1^{c}$ & $0.4^{\mathrm{b}}$ & $0.6^{\mathrm{a}}$ \\
\hline NAR & & $0.5^{b}$ & $0.7^{\mathrm{a}}$ & $0.8^{\mathrm{a}}$ \\
\hline$A$ & & $0.4^{\mathrm{b}}$ & $0.6^{\mathrm{a}}$ & $0.7^{\mathrm{a}}$ \\
\hline $\mathrm{Ci}$ & & 0.2 & 0.1 & $0.2^{\text {n.s. }}$ \\
\hline$E$ & & $0.2^{\mathrm{b}}$ & $0.4^{\mathrm{a}}$ & $0.5^{\mathrm{a}}$ \\
\hline gs & \multirow{8}{*}{ Photosynthesis } & 0.5 & 0.5 & $0.4^{\text {n.s. }}$ \\
\hline WUE & & $0.2^{\mathrm{b}}$ & $0.3^{\mathrm{ab}}$ & $0.4^{\mathrm{a}}$ \\
\hline$\Phi c$ & & $0.2^{\mathrm{b}}$ & $0.6^{\mathrm{a}}$ & $0.6^{a}$ \\
\hline$F_{\mathrm{V}} / F_{\mathrm{M}}$ & & $0.3^{\mathrm{a}}$ & $0.0^{\mathrm{b}}$ & $0.0^{\mathrm{b}}$ \\
\hline $\mathrm{Rd}$ & & $0.6^{a}$ & $0.3^{\mathrm{b}}$ & $0.1^{c}$ \\
\hline IAA & & $0.2^{\mathrm{b}}$ & $0.8^{\mathrm{a}}$ & $0.9^{a}$ \\
\hline $\mathrm{H}_{2} \mathrm{O}_{2}$ & & $0.8^{\mathrm{a}}$ & $0.4^{\mathrm{b}}$ & $0.3^{\mathrm{b}}$ \\
\hline MDA & & $0.8^{\mathrm{a}}$ & $0.7^{\mathrm{ab}}$ & $0.6^{\mathrm{b}}$ \\
\hline Cel. leaf & \multirow{6}{*}{ Biochemical } & 0.2 & 0.2 & $0.3^{\text {n.s. }}$ \\
\hline Cel. stem & & 0.1 & 0.1 & $0.1^{\text {n.s. }}$ \\
\hline Hem. leaf & & 0.2 & 0.3 & $0.2^{\text {n.s. }}$ \\
\hline Hem. stem & & 0.1 & 0.1 & $0.1^{\text {n.s. }}$ \\
\hline Lig. leaf & & 0.2 & 0.3 & $0.2^{\text {n.s. }}$ \\
\hline Lig. stem & & 0.1 & 0.1 & $0.2^{\text {n.s. }}$ \\
\hline
\end{tabular}


Lower oxidative damage and cell wall loosening, mediated or not by auxin, as part of the tolerance mechanism of Paubrasilia echinata morphotypes in the shade and full sun

morphotypes (Fig. 5A) as well as among the stems of all the three morphotypes (Fig. 5B). The hemicelluloses contents in the leaves of the three morphotypes did not vary between the treatments (Fig. 5C). Regarding the stems, the highest value was observed in the SM in the full sun, while in the other two morphotypes this result occurred in the shade (Fig. 5D). Regarding lignin, the full sun stimulated its deposition on the leaves (Fig. 5E) and on the stems (Fig. 5F) of the three morphotypes. Comparing the morphotypes within each treatment, the leaf cellulose levels did not vary between them in the two conditions (Fig. 5A). In the stem, the SM showed the highest value in each treatment (Fig. 5B) when compared to the other morphotypes. For hemicelluloses, their values in the leaves were higher in LM
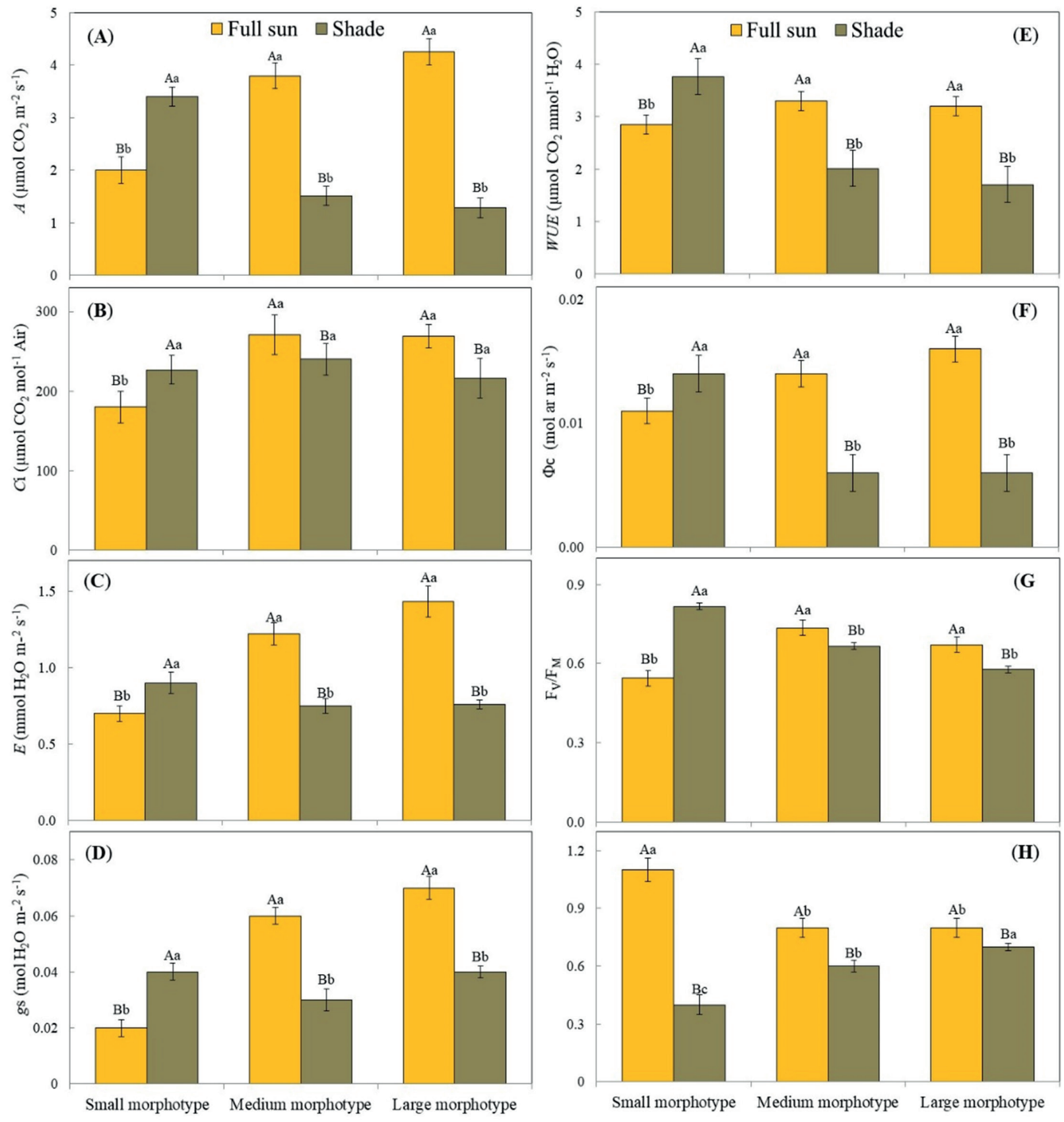

Figure 3. Gas-exchange variables, $F_{\mathrm{V}} / F_{\mathrm{M}}$ and $\mathrm{Rd}$ in leaf of the small, medium and large morphotypes of Paubrasilia echinata under full sun and shade. The bars represent the standard error of the mean. $A$ is net $\mathrm{CO}_{2}$ assimilation rate $(\mathbf{A})$, gs is stomatal conductance to water vapor $(\mathbf{D}), E$ is transpiration $(\mathbf{C}), C$ is internal $\mathrm{CO}_{2}$ concentration $(\mathbf{B}), W U E$ is water-use efficiency $(\mathbf{E})$, $\Phi$ c is efficiency instantaneous of carboxylation $(\mathbf{F}), F_{\mathrm{V}} / F_{\mathrm{M}}$ is maximum photochemical yield of PSII $(\mathbf{G})$ and $\mathrm{Rd}$ is respiration rate in the dark $(\mathbf{H})$. The differences between treatments are indicated by capital letters (A, B), whereas the differences between morphotypes within each treatment are indicated by lower case letters $(a, b)$ by Tukey's test $(P<0.05)$. 
under two treatments (Fig. 5C) while in the stem, the MM and LM stood out for their highest values in both irradiance conditions (Fig. 5D). Regarding lignin, the content of this polymer in the leaves did not vary between the morphotypes within each treatment (Fig. 5E). This same response was observed in the stem of plants in the shade (Fig. 5F). In the full sun, however, the highest levels of stem lignin were found in the MM and LM (Fig. 5F). The three cell wall polymers presented the lowest PI compared to the other variables ( $\leq 0.3$ ) and no significant difference between the morphotypes (Tab. 2). By qualitatively comparing the plant organs, the stem of the three morphotypes showed a higher amount of polymers than the leaves (Fig. 5A-F).

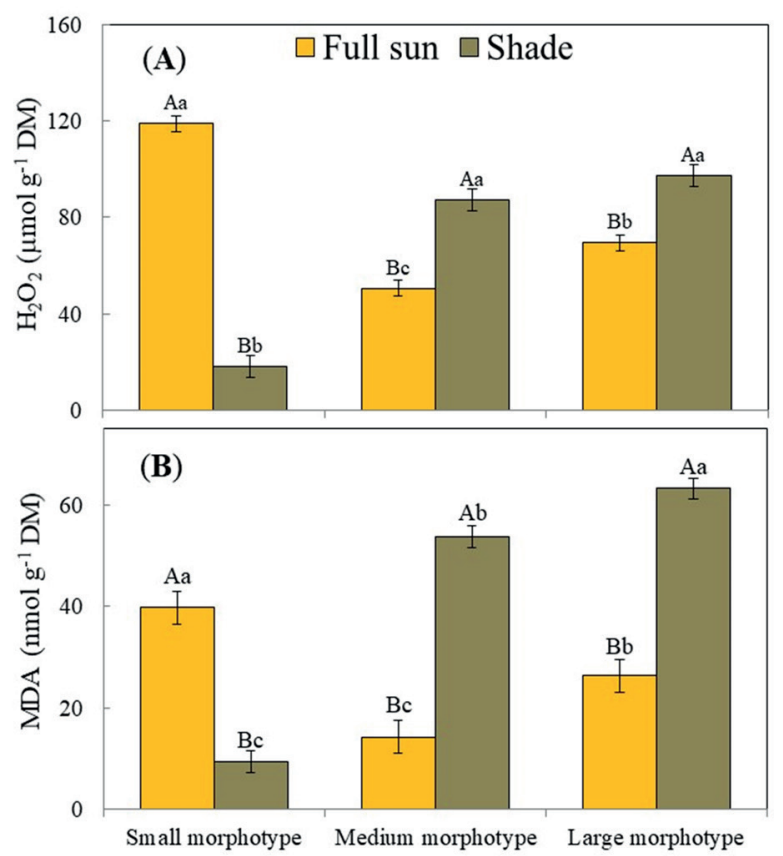

Figure 4. Hydrogen peroxide $\left(\mathrm{H}_{2} \mathrm{O}_{2}\right)(\mathbf{A})$ and malondialdehyde (MDA) (B) in leaf of the small, medium and large morphotypes of Paubrasilia echinata under full sun and shade. The bars represent the standard error of the mean. The differences between treatments are indicated by capital letters (A, B), whereas the differences between morphotypes within each treatment are indicated by lower case letters $(\mathrm{a}, \mathrm{b})$ by Tukey's test $(P<0.05)$.

\section{Discussion}

The highest values of growth (height, total dry mass, relative growth rate-RGR, and net assimilation rate-NAR) and net carbon assimilation rates $(A)$ of the SM were found in the shaded condition, and of the MM were observed in the full sun, confirming the shade-tolerant habit of the former morphotype (Mengarda et al. 2009) and the sun-tolerant habit of the latter (Gama et al. 2019). These results also reinforce the concept that sun-tolerant and shade-tolerant species are generally recognized by their higher growth and photosynthesis rate under intense and low solar irradiance, respectively (Finegan 1984; Swaine \& Whitmore 1988; Whitmore 1991).

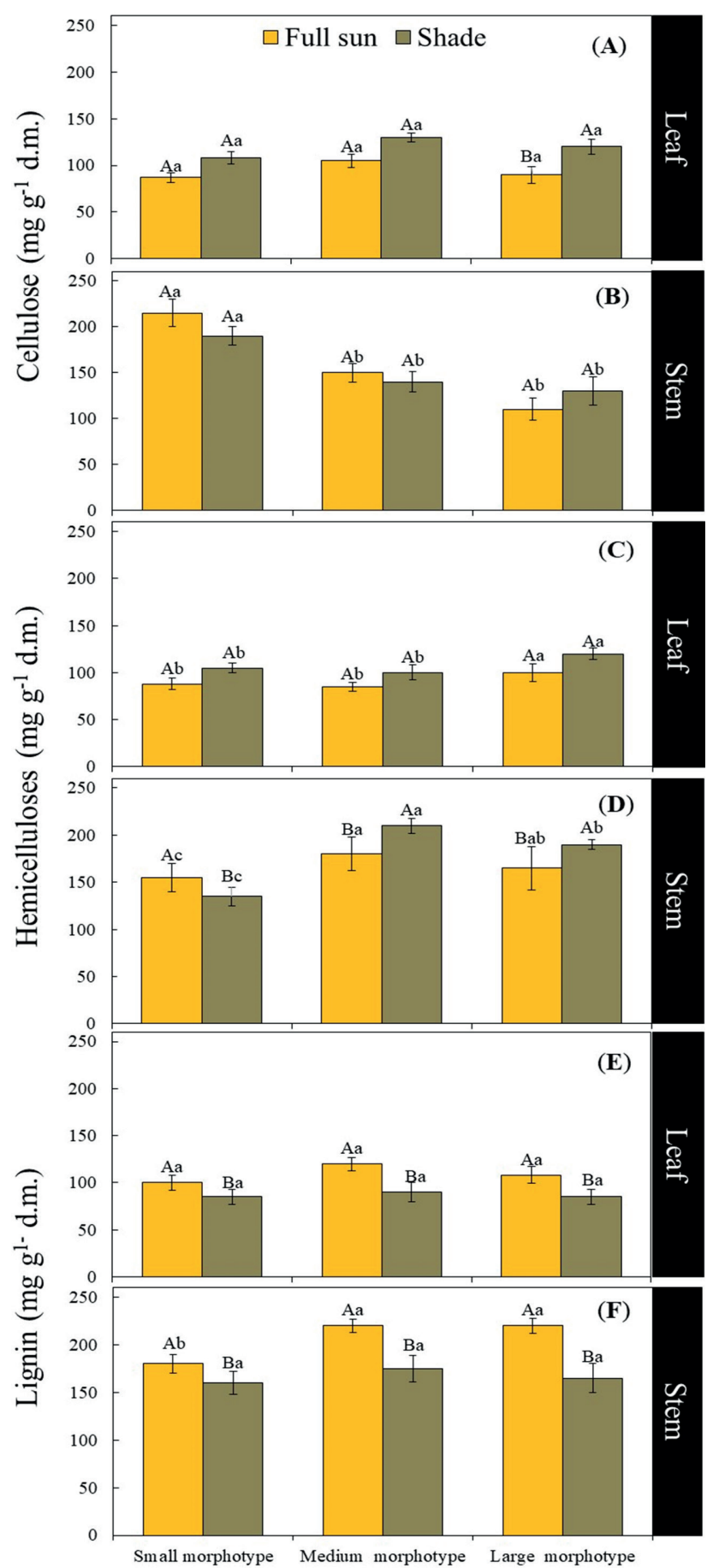

Figure 5. Concentrations of cellulose (A, B), hemicelluloses (C, D) and lignin (E, F) in leaf and stem of the small, medium and large morphotypes of Paubrasilia echinata under full sun and shade. The bars represent the standard error of the mean. The differences between treatments are indicated by capital letters (A, B), whereas the differences between morphotypes within each treatment are indicated by lower case letters $(\mathrm{a}, \mathrm{b})$ by Tukey's test $(P<0.05)$. 
The higher adjustment capacity (plasticity index-PI) of growth and $A$ of the sun-tolerant morphotypes compared to the shade-tolerant one reinforces the tendency of the pioneers (sun-tolerant) to exhibit a higher adjustment capacity compared to non-pioneer (shade-tolerant) tropical species (Portes et al. 2010; Souza \& Válio 2003; Valladares et al. 2000). Differently than expected, it seems that the lower adjustment capacity of the shade-tolerant morphotype did not prevent its wide geographic distribution along the southeastern and northeastern coasts of Brazil, estimated at $3,000 \mathrm{~km}$ (Juchum et al. 2008). In contrast, the higher adjustment capacity of growth and $A$ parameters for the two sun-tolerant morphotypes under contrasting solar irradiances limited the occurrence of these morphotypes to the coast of the states of Rio de Janeiro, Espírito Santo, and Bahia, estimated in approximately $1,960 \mathrm{~km}$, and the restriction of the large morphotype to the southeastern region of Bahia (Juchum et al. 2008). Therefore, the large geographical distribution of pioneer species (suntolerant) explained by their higher adjustment capacity (Whitmore 1991) does not seem to apply to the sun-tolerant morphotypes. The geographical distribution of the sun and shade-tolerant morphotypes of $P$. echinata is likely determined by unknown processes of germination and seedling establishment. However, one should be careful not to extrapolate the results obtained in the juvenile stage to the adult one (Souza \& Válio 2003) due to the deep morphological and physiological changes that take place in the ontogeny of $P$. echinata from the initial growth phase to the adult stage (Zani et al. 2017).

The strongly limited growth of the two sun-tolerant morphotypes in the shade condition was apparently associated with the auxin concentration. It is well known that different types of stress, including low light intensity, can block the signalling of the genes involved in the synthesis of growth hormones like auxins (Kurepin et al. 2007). Thus, the strong growth inhibition of the two suntolerant morphotypes in the shade seems to be a direct result of the very low levels of auxin-IAA in this light limiting condition. The significant reduction of the amount of IAA in the sun-tolerant morphotypes under shaded conditions might have affected the cell expansion by inhibiting the enzymatic hydrolysis of hemicelluloses and, consequently, stem elongation (Sofo et al. 2004; Baroniya et al. 2014; Kataria et al. 2014). Thus, the more intense oxidative stress in sun-tolerant morphotypes in shaded conditions might have affected the IAA concentration, resulting in intense inhibition of the stem axial growth under low solar irradiance. Different than expected, the limited growth of the shade-tolerant morphotype in the full sun condition was not accompanied by a decrease in IAA concentration in this growth inhibitory irradiance. Possibly, the modest inhibition of growth in the shade-tolerant morphotype in the full sun environment to be the result of the photosynthesis inhibition and increase of oxidant reactions in this lightinhibiting condition, as discussed later.

Even with the differences in growth between the shade-tolerant and the sun-tolerant morphotypes under contrasting solar irradiances, the root:shoot (R:S) ratio of the three morphotypes under the full sun condition was higher than in the shade. The higher investment in the root system at the expense of the shoot is one of the adaptive strategies adopted in response to the increase of solar irradiance intensity (Lambers et al. 2008). Similar to the biomass allocation between roots and shoots, the three morphotypes showed a similar adaptive strategy for leaf morphology. All the three morphotypes invested in the leaf blade thickening in the full sun condition, indicated by the high leaf mass area (LMA). The increase in LMA represents one of the tropical tree responses to the high intensity of solar irradiance during the early growth, increasing the resistance to water loss and to photo-oxidative damages, regardless of the successional class (Souza \& Válio 2003).

The highest $A$ values for SM under the shade and for $\mathrm{MM}$ in the full sun condition confirmed the tolerance of the first morphotype to the shade (Mengarda et al. 2009) and of the latter morphotype to full sun (Gama et al. 2019). The inhibition of $A$ in SM in the full sun condition, and of MM and LM in the shade can be explained by the oxidative action of free radicals on the RuBisCO pathway under these stress conditions (Thach et al. 2007). In the inhibitory solar irradiances typical of each morphotype, the high content of $\mathrm{H}_{2} \mathrm{O}_{2}$ apparently stimulated the lipid peroxidation of membranes, indicated by an increase in the content of aldehydes such as malondialdehyde (MDA), often used as an indicator of oxidative damage (Amin et al. 2009). Thus, under stress like high and low solar irradiance, $\mathrm{H}_{2} \mathrm{O}_{2}$ may destabilize several proteins through the oxidation of the cysteine group (Møller et al. 2007), as must have occurred with $\mathrm{RuBisCO}$ in the shade-tolerant morphotype under the full sun condition and in the sun-tolerant morphotypes in the shade, as suggested by the higher contents of $\mathrm{H}_{2} \mathrm{O}_{2}$ and MDA under these inhibitory solar irradiances. At more severe levels, the lipid peroxidation may affect the membrane integrity, impairing the functioning of the cell due to the loss of electrolytes, rapid desiccation, and cell death (Halliwell 2006). In this respect, it seems that the shade-tolerant morphotypes were more sensitive to the stressful solar irradiance than the sun-tolerant morphotypes. This may be confirmed by the high PI of the oxidative metabolism variables and the highest energy consumption for SM, as suggested by the highest respiration in the dark-Rd compared to the other morphotypes in the full sun condition. The $A$ inhibition of the morphotypes in photo-inhibitory treatment can also be explained by the lower photochemical efficiency of photosystem II $\left(F_{\mathrm{V}} / F_{\mathrm{M}}\right)$. Thus, the photo-inhibitory conditions may have affected the fluorescence of chlorophyll $a$, and, consequently, limited the reducing power required for $\mathrm{CO}_{2}$ fixation in the $\mathrm{RuBis} C \mathrm{C}$ 


\section{Vinícius Novo Gama, Leonardo Valandro Zanetti, Bernardo Pretti Becacici Macieira and Geraldo Rogério Faustini Cuzzuol}

pathway, in the three morphotypes, under these stress conditions (Gama et al. 2019) as suggested by the lower intercellular $\mathrm{CO}_{2}$ concentration- $\mathrm{Ci}$ and instantaneous rate of carboxylation $(\Phi c)$ of SM under the full sun condition, and of MM and LM in the shade.

Still considering the relation between photosynthesis and oxidative stress, the lower stomatal conductance ( $g s$ ) of the sun-tolerant morphotypes under shade, and of the shade-tolerant plants under full sun can be attributed to the higher $\mathrm{H}_{2} \mathrm{O}_{2}$ concentrations under these conditions. The accumulation of $\mathrm{H}_{2} \mathrm{O}_{2}$ promotes the opening of calcium channels on the membrane of the guard cells, leading to stomatal closure (Pel et al. 2000) and decline of gs, since it should have occurred with the sun-tolerant morphotypes under shade conditions, and with the shade-tolerant plants under full sun. Consequently, less water was lost to transpiration $(E)$ by the sun-tolerant morphotypes in the shade, and by the shade-tolerant ones under full sun. This resulted in the low water-use efficiency (WUE) and in the inhibition of $A$ and biomass production of the two sun-tolerant morphotypes in the shade, and in the shadetolerant morphotype under full sun. These results are consistent with the information that tropical pioneer species (sun-tolerant) are more efficient in WUE than non-pioneer ones (shade-tolerant) in highly illuminated environments (Siegert \& Levia 2011).

Considering that most of the photo-assimilated $\mathrm{CO}_{2}$ enters the route of the cell wall polymers-CWP synthesis (Hartmann \& Trumbore 2016), higher levels of these compounds were expected in the photo-promoted condition of each morphotype. However, the opposite effect was observed for stem hemicelluloses. This response seems to be related to the morphotype habits. The decline in stem hemicelluloses in photo-promoted condition may be indicative of cell wall loosening and cell expansion (Sasidharan et al. 2014), which may have contributed to the stem lengthening of the SM in the shade and of the other two morphotypes in the full sun condition. The decreased level of hemicelluloses in the stem of the shade-tolerant morphotype under shade conditions suggests an inhibitory effect of the low oxidative metabolism $\left(\downarrow \mathrm{H}_{2} \mathrm{O}_{2}\right.$ and MDA, Fig. 6) of this irradiance on hemicellulose hydrolysis (Le Gall et al. 2015). The same effects might have occurred in the sun-tolerant morphotypes under full sun conditions (Fig. 6). The lack of difference in the levels of leaf cellulose and hemicelluloses levels between the treatments in the three morphotypes might be due to the low proportion of these compounds in these structures, as observed by Macieira et al. (2020) in pioneer (sun-tolerant) and non-pioneer (shade-tolerant) tropical tree species. The similarity in the cellulose content of the three morphotypes exposed to contrasting irradiances confirms the resilience of this polymer to variations in light intensity (Le Gall et al. 2015). The higher deposition of lignin in the three morphotypes under full sun conditions confirms the positive relationship between this CWP and the irradiance intensity in plant tissues (Cabané et al. 2012), in which the CWP acts as a barrier to heating associated with higher irradiance (Akgül et al. 2007). The higher stem lignification of MM and LM in the full sun compared to the SM, seems to be a characteristic of the heliophile habit of those first morphotypes. In this sense, the higher stem lignification of the full sun-tolerant morphotypes likely favored the water transport in the vessels due to the hydrophilic property of lignin (Novaes et al. 2010). This possibility is supported by the higher WUE among the morphotypes under the full sun condition compared to the shade-tolerant morphotype under this irradiance regime.

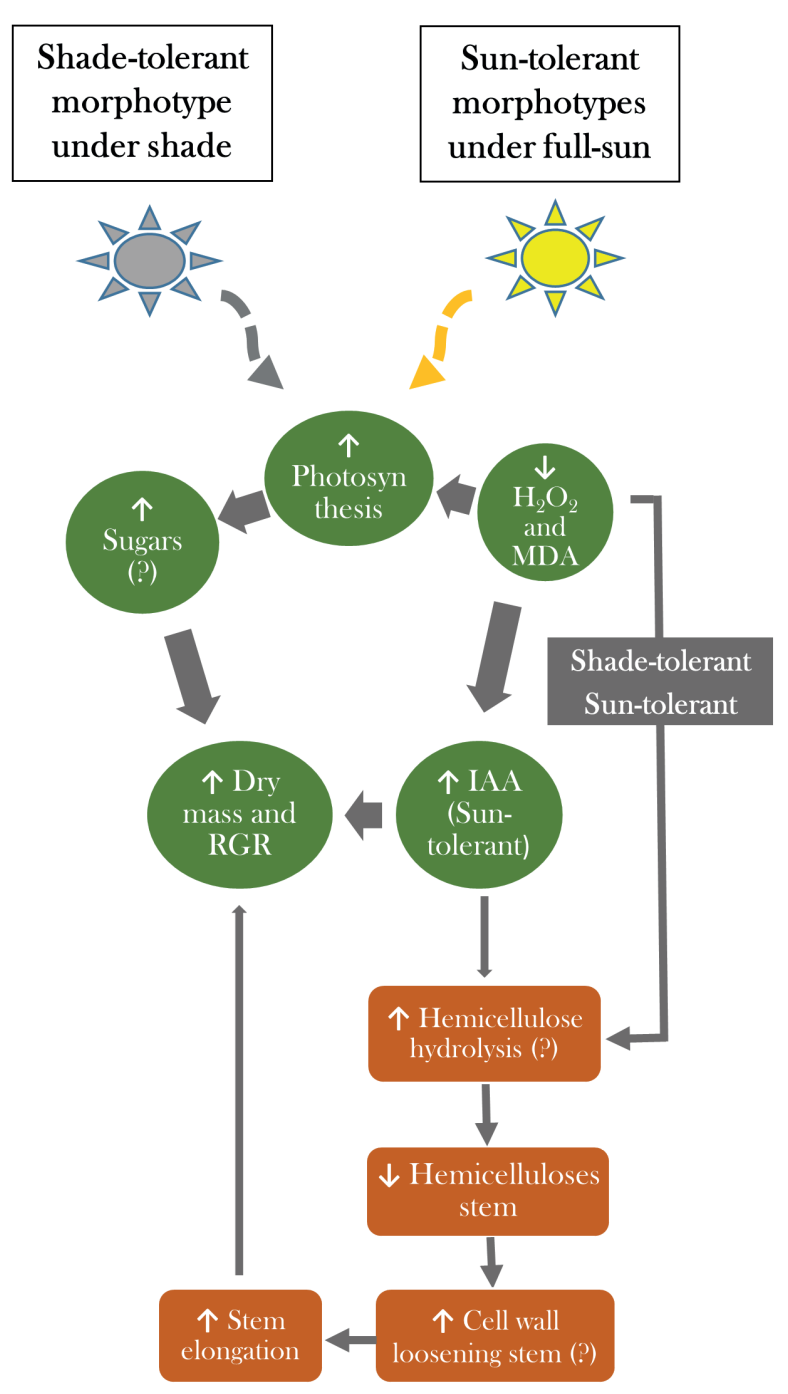

Figure 6. Mechanisms of morphological and physiological reactions of the shade-tolerant ecotype and sun-tolerant ecotypes of Paubrasilia echinata under photo-promoter conditions of each morphotype.

We conclude that the shade-tolerant and sun-tolerant morphotypes of P. echinata showed consistent morphological and physiological responses in contrasting solar irradiances 
(Fig. 6). The results validated the hypothesis that the growth and photosynthesis of SM (shade-tolerant) were inhibited under the full sun condition, and the MM and LM (sun-tolerant) in the shade, in which the oxidative reactions, indicated by the $\mathrm{H}_{2} \mathrm{O}_{2}$ and MDA contents were higher. The hypothesis of auxin content of the MM and LM to be inhibited under shade was also accepted. However, this hypothesis was rejected for the SM (shade-tolerant morphotype) when exposed to the full sun condition that inhibited its growth. The hypothesis that CWP are stimulated by the photo-promoter condition of each morphotype was also rejected, although the decline in stem hemicelluloses under photo-promoted condition may have contributed to the stem lengthening of the SM in the shade and of the other two morphotypes under full sun. The higher stem lignification of the MM and LM under full sun compared to the SM seems to be a characteristic of the heliophile habit of those first morphotypes. This study revealed the integration of oxidative reactions and hemicelluloses with these two functional classes of plants; therefore, it has contributed to advances in the understanding of the physiological mechanisms of tropical trees tolerant to shade and full sunlight. In this sense, the lower oxidant metabolism favors the loosening of the cell wall (lower hemicelluloses content) of the three morphotypes in the photo-promoter treatments, and this process, mediated or not by the greater expression IAA, seems to represent an essential part of the tolerance mechanism of $P$. echinata morphotypes to shade and full sunlight (Fig. 6).

The success of the shade-tolerant and of the sun-tolerant morphotypes under solar irradiance seems to be due to an efficient antioxidative system of SM in the shade, and MM and LM in the full sun. This resulted in higher A, photochemical efficiency, and growth under solar irradiance. Moreover, there is a high IAA content of sun-tolerant and shade-tolerant morphotypes under full irradiance. This information shows the importance of performing a molecular investigation of the morphotypes in order to allow their taxonomic separation of the SM (shade-tolerant) from the MM and LM (sun-tolerant). This conclusion supports the studies of Juchum et al. (2008) and Gagnon et al. (2016), which claimed that $P$. echinata in fact designates a species complex, and that in the future, these morphotypes will likely be classified in subspecific taxa or even in new species within the genus Paubrasilia. The morphological and physiological differences between the morphotypes of P. echinata (Fig. 6) suggest that this biological material is indicated as a good model for ecophysiological studies of shade-tolerant and sun-tolerant tropical trees under contrasting solar irradiances or under other microclimatic conditions such as rising of temperature, $\mathrm{CO}_{2}$, and UV-B; flooding; and drought for potential scenarios of climatic changes for the Brazilian tropical forests in the next 50 years (IPCC 2014).

\section{Acknowledgements}

This work was supported by the Fundação de Amparo à Pesquisa e Inovação do Espírito Santo - FAPES, Brazil (Grant No. 207/2017). The first author thanks Coordenação de Aperfeiçoamento de Pessoal de Nível Superior - CAPES, Brazil, for the scholarship. We thank Arcos Marco Raposo company for donating Paubrasilia echinata seeds.

\section{References}

Akgül M, Çöpür Y, Temiz S. 2007. A comparison of kraft and kraft-sodium borohydrate brutia pine pulps. Building and Environment 42: 2586-2590.

Alexieva V, Sergiev I, Mapelli S, Karanov E. 2001. The effect of drought and ultraviolet radiation on growth and stress markers in pea and wheat. Plant, Cell \& Environment 24: 1337-1344.

Amin B, Ghorbanli M, Haj R, Mozafarih H. 2009. Evaluation of interaction effect of drought stress with ascorbate and salicylic acid on some of physiological and biochemical parameters in Okra (Hibiscus esculentus L.). Research Journal of Biological Sciences 4: 380-387.

Asada K, Asada K. 1999. The water-water cycle in chloroplasts: Scavenging of active oxygens and dissipation of excess photons. Annual Review of Plant Physiology and Plant Molecular Biology 50: 601-639.

Baroniya SS, Kataria S, Pandey GP, Guruprasad KN. 2014. Growth, photosynthesis and nitrogen metabolism in soybean varieties after exclusion of the UV-B and UV-A/B components of solar radiation. The Crop Journal 2: 388-397.

Brendel O, Losetta PPMG, Stewart D. 2000. A rapid and simple method to isolate pure alpha cellulose. Phytochemical Analysis 11: 7-10.

Buege JA, Aust SD. 1978. Microsomal lipid peroxidation. Methods in Enzymology 52: 302-310.

Butler WL. 1978. Energy distribution in the photochemical apparatus of photosynthesis. Annual Review of Plant Biology 29: 345-378.

Cabané M, Afif D, Hawkins S. 2012. Lignins and abiotic stresses. Advances in Botanical Research 61: 219-262.

Carpita NC, Kanabus J. 1987. Extraction of starch by dimethyl sulfoxide and quantitation by enzymatic assay. Analytical Biochemistry 161: 132-139.

Choudhury FK, Rivero RM, Blumwald E, Mittler R. 2017. Reactive oxygen species, abiotic stress and stress combination. The Plant Journal 90: 856-867.

Contin DR, Soriani HH, Hernández I, Furriel RPM, Munné-Bosch S, Martinez CA. 2014. Antioxidant and photoprotective defenses in response to gradual water stress under low and high irradiance in two Malvaceae tree species used for tropical forest restoration. Trees - Structure and Function 28: 1705-1722.

Cuzzuol GRF, Milanez CRD, Gomes JML, Labate CA, Canal EC. 2013. Relationship between N, P, and K and the quality and Stem structural characteristics of Caesalpinia echinata Lam. plants. Trees - Structure and Function 27: 1477-1484.

Dos Santos WD, Ferrarese ML, Nakamura CV, Mourão KSM, Mangolin CA, Ferrarese-Filho O. 2008. Soybean (Glycine max) root lignification induced by ferulic acid. The possible mode of action. Journal of Chemical Ecology 34: 1230-1241.

Esposito MP, Nakazato RK, Pedroso ANV, et al. 2018. Oxidant-antioxidant balance and tolerance against oxidative stress in pioneer and nonpioneer tree species from the remaining Atlantic Forest. Science of the Total Environment 625: 382-393.

Favaretto VF, Martinez CA, Soriani HH, Furriel RPM. 2011. Differential responses of antioxidant enzymes in pioneer and late-successional tropical tree species grown under sun and shade conditions. Environmental and Experimental Botany 70: 20-28.

Finegan B. 1984. Forest succession. Nature 312: 109-114.

Gaburro TA, Zanetti LV, Gama VN, Milanez CRD, Cuzzuol GRF. 2015. Physiological variables related to photosynthesis are more plastic than 


\section{Vinícius Novo Gama, Leonardo Valandro Zanetti, Bernardo Pretti Becacici Macieira and Geraldo Rogério Faustini Cuzzuol}

the morphological and biochemistry in non-pioneer tropical trees under contrasting irradiance. Brazilian Journal of Botany 38: 39-49.

Gagnon E, Bruneau A, Hughes CE, Queiroz LP, Lewis GP. 2016. A new generic system for the pantropical Caesalpinia group (Leguminosae). PhytoKeys 71: 1-160.

Gama VN, Macieira BPB, Zanetti LV, et al. 2019. Ecophysiological responses of medium morphotype plants of Paubrasilia echinata raised under full sunlight and natural shade. Revista Árvore 43: e430407. doi: 10.1590/1806-90882019000400007

Gong WZ, Qi PF, Du JB, et al. 2014. Transcriptome analysis of shade induced inhibition on leaf size in relay intercropped soybean. PLOS ONE 9: e98465. doi: 10.1371/journal.pone.0098465

Guo JM, Xin YY, Yin XB. 2010. Selective differentiation of indoleacetic acid and indolebutyric acid using colorimetric recognition after ehrlich reaction. Journal of Agricultural and Food Chemistry 58: 6556-6561.

Halliwell B. 2006. Reactive species and antioxidants. Redox biology is a fundamental theme of aerobic life. Plant Physiology 141: 312-322.

Hartmann H, Trumbore S. 2016. Understanding the roles of nonstructural carbohydrates in forest trees-from what we can measure to what we want to know. New Phytologist 211: 386-403.

Huc R, Ferhi A, Guehl JM. 1994. Pioneer and late stage tropical rainforest tree species (French Guiana) growing under common conditions differ in leaf gas exchange regulation, carbon isotope discrimination and leaf water potential. Oecologia 99: 297-305.

IPCC. 2014. Annex II: Glossary. In: Barros VR, Field CB, Dokken DJ, et al. (eds.) IPCC: Climate Change 2014 - Impacts, Adaptation, and Vulnerability. Part B: Regional Aspects. Contribution of Working Group II to the Fifth Assessment Report of the Intergovernmental Panel on Climate Change. Cambridge, Cambridge University Press. p. 1757-1776.

Juchum FS, Costa MA, Amorim AM, Corrêa RX. 2008. Phylogenetic relationships among morphotypes of Caesalpinia echinata lam. (Caesalpinioideae: Leguminosae) evidenced by trnL intron sequences. Naturwissenschaften 95: 1085-1091.

Kataria S, Jajoo A, Guruprasad KN. 2014. Impact of increasing Ultraviolet-B (UV-B) radiation on photosynthetic processes. Journal of Photochemistry and Photobiology B: Biology 137: 55-66.

Kitajima K. 1994. Relative importance of photosynthetic traits and allocation patterns as correlates of seedling shade tolerance of 13 tropical trees. Oecologia 98: 419-428.

Kurepin LV, Emery RJN, Pharis RP, Reid DM. 2007. Uncoupling light quality from light irradiance effects in Helianthus annuus shoots: putative roles for plant hormones in leaf and internode growth. Journal of Experimental Botany 58: 2145-2157.

Lambers H, Poorter H. 1992. Inherent variation in growth rate between higher plants: A search for physiological causes and ecological consequences. Advances in Ecological Research 23: 187-261.

Lambers H, Chapin III FS, Pons TL. 2008. Plant Physiological Ecology. 2nd edn. New York, Springer.

Le Gall H, Philippe F, Domon JM, Gillet F, Pelloux J, Rayon C. 2015. Cell wall metabolism in response to abiotic stress. Plants 4: 112-166.

Liu S, Yang R, Ren B, Wang M, Ma M. 2016. Differences in photosynthetic capacity, chlorophyll fluorescence, and antioxidant system between invasive Alnus formosana and its native congener in response to different irradiance levels. Botany 94: 1087-1101.

Macieira BPB, Locosselli GM, Buckeridge MS, Hartmannc H, Cuzzuol GRF. 2020. Stem and leaf functional traits allow successional classification in six pioneer and non-pioneer tree species in Tropical Moist Broadleaved Forests. Ecological Indicators 113: 106254. doi: 10.1016/j.ecolind.2020.106254

Mengarda LHG, Souza RLF, Campostrini E, Reis FO, Vendrame WA, Cuzzuol GRF. 2009. Light as an indicator of ecological succession in brazilwood (Caesalpinia echinata Lam.). Brazilian Journal of Plant Physiology 21: 55-64.

Møller IM, Jensen PE, Hansson A. 2007. Oxidative modifications to cellular components in plants. Annual Review of Plant Biology 58: 459-481.
Nogueira A, Martinez CA, Ferreira LL, Prado CHBA. 2004. Photosynthesis and water use efficiency in twenty tropical tree species of differing succession status in a Brazilian reforestation. Photosynthetica 42: 351-356.

Novaes E, Kirst M, Chiang V, Winter-Sederoff H, Sederoff R. 2010. Lignin and biomass: a negative correlation for wood formation and lignin content in trees. Plant Physiology 154: 555-561.

Paradizo IC, Macieira BPB, Gama VN, Zanetti LV, Cuzzuol GRF. 2015. Phenotypic plasticity as indicator of non-pioneer trees more tolerant to intense irradiance. Pesquisa Florestal Brasileira 35: 359-369.

Pel ZM, Murata Y, Benning G, et al. 2000. Calcium channels activated by hydrogen peroxide mediate abscisic acid signalling in guard cells. Nature 406: 731-734.

Portela FCS, Macieira BPB, Zanetti LV, et al. 2019. How does Cariniana estrellensis respond to different irradiance levels? Journal of Forestry Research 30: 31-44.

Portes MT, Damineli DSC, Ribeiro RV, Monteiro JAF, Souza GM. 2010. Evidence of higher photosynthetic plasticity in the early successional Guazuma ulmifolia Lam. compared to the late successional Hymenaea courbaril L. grown in contrasting light environments. Brazilian Journal of Biology 70: 75-83.

Ribeiro RV, Souza GM, Oliveira RF, Machado EC. 2005. Photosynthetic responses of tropical tree species from different successional groups under contrasting irradiance conditions. Brazilian Journal of Botany 28: $149-161$

Santos RD, Barreto WO, Araújo WS, et al. 2004. Levantamento expedito dos solos das Reservas Florestais de Linhares e Sooretama no estado do Espírito Santo. Boletim de Pesquisa e Desenvolvimento 49: 1-68.

Sasidharan R, Keuskamp DH, Kooke R, Voesenek LA, Pierik R. 2014. Interactions between auxin, microtubules and XTHs mediate green shade-induced petiole elongation in Arabidopsis. PLOS ONE 9: e90587. doi: 10.1371/journal.pone.0090587

Schädel C, Blöchl A, Richter A, Hoch G. 2010. Quantification and monosaccharide composition of hemicelluloses from different plant functional types. Plant Physiology and Biochemistry 48: 1-8.

Siegert CM, Levia DF. 2011. Stomatal conductance and transpiration of co-occurring seedlings with varying shade tolerance. Trees-Structural and Functional 25: 1091-1102.

Sofo A, Dichio B, Xiloyannis C, Masia A. 2004. Effects of different irradiance levels on some antioxidant enzymes and on malondialdehyde content during rewatering in olive tree. Plant Science 166: 293-302.

Souza RP, Válio IFM. 2003. Seedling growth of fifteen Brazilian tropical tree species differing in successional status. Brazilian Journal of Botany 26: 35-47.

Swaine MD, Whitmore TC. 1988. On the definition of ecological species groups in tropical rain forests. Vegetatio 75: 81-86.

Thach LB, Shapcott A, Schmidt S, Critchley C. 2007. The OJIP fast fluorescence rise characterizes Graptophyllum species and their stress responses. Photosynthesis Research 94: 423-436.

Thomas SC, Martin AR. 2012. Carbon content of tree tissues: a synthesis. Forests 3: 332-352.

Valladares F, Wright SJ, Lasso E, Kitajima K, Pearcy RW. 2000. Plastic phenotypic response to light of 16 congeneric shrubs from a Panamanian rainforest. Ecology 81: 1925-1936.

Valladares F, Sanchez-Gomez D, Zavala MA. 2006. Quantitative estimation of phenotypic plasticity: bridging the gap between the evolutionary concept and its ecological applications. Journal of Ecology 94: 11031116.

Whitmore TC. 1991. Tropical rain forest dynamics and its implications for management. In: Gomez-Pompa A, Whitmore TC, Halley M. (eds.) Rain forest regeneration and management. New York, Parthenon Publishing Group and UNESCO. p. 67-90.

Zani LB, Macieira BPB, Corte VB, Milanez CRD, Cuzzuol GRF. 2017. The vessel elements and hemicelluloses as the most plastic structural components of the brazilwood ontogeny (Caesalpinia echinata Lam.) medium morphotype. Brazilian Journal of Botany 40: 793-800. 